\title{
(2) OPEN ACCESS \\ Tobacco control within and beyond WHO MPOWER: outcomes from Taiwan SimSmoke
}

\author{
Mattia Sanna (1) , ${ }^{1}$ Wayne Gao, ${ }^{1}$ Ya-Wen Chiu, ${ }^{1}$ Hung-Yi Chiou, ${ }^{2}$ Yi-Hua Chen, ${ }^{2}$ \\ Chi-Pang Wen, ${ }^{3,4}$ David Theodore Levy ${ }^{5}$
}

\begin{abstract}
- Additional material is published online only. To view, please visit the journal online (http://dx.doi.org/10.1136/ tobaccocontrol-2018-054544).
\end{abstract}

'Master's Program in Global Health and Development, Taipei Medical University, Taipei, Taiwan

${ }^{2}$ College of Public Health, Taipei Medical University, Taipei,

Taiwan

${ }^{3}$ Institute of Population Health

Sciences, National Health Research Institutes, Zhunan, Taiwan

${ }^{4}$ China Medical University Hospital, Taichung, Taiwan ${ }^{5}$ Department of Oncology, Lombardi Comprehensive Cancer Center, Georgetown University Medical Center, Washington, District of Columbia, USA

\section{Correspondence to} Dr Wayne Gao, Master's Program in Global Health and Development, Taipei Medical University, Taipei 110 Taiwan; waynegao@tmu.edu.tw

MS and WG contributed equally.

Received 5 June 2018 Revised 25 September 2018 Accepted 9 October 2018 Published Online First 5 November 2018

\section{ABSTRACT \\ Introduction Adult smoking prevalence in Taiwan} rapidly declined from $26.5 \%$ in 2005 to $20.0 \%$ in 2015 . Nevertheless, future projections on smoking-attributable deaths and current per capita consumption do not paint an equally bright picture.

Methods We used SimSmoke, a tobacco control simulation model to assess the impact of tax increases and other policies by predicting past and projecting over future decades smoking rates and smoking-attributable mortality.

Results The model accurately depicts the decline in smoking prevalence observed in Taiwan from 2000 to 2015. Nonetheless, under the 'status quo' scenario, smoking-attributable mortality is projected to continue growing, peaking at 26602 annual deaths in 2039 and cumulative deaths $>1$ million by 2044 . By comparing projections with current policies with a counterfactual scenario based on the 2000 policy levels, SimSmoke estimates that tobacco control in Taiwan has been able to reduce smoking prevalence by $30 \%$ in 2015 with 450000 fewer smoking-attributable deaths by 2060 . Modified scenarios show that doubling the retail price of cigarettes and fully implementing the remaining MPOWER measures would avert approximately 45000 lives by 2040 and 130000 by 2060 .

Conclusions Tobacco will be a leading cause of death in Taiwan for the coming decades, showing yet again the long-term consequences of smoking on public health. The MPOWER package, even if adopted at the highest level with a large tax increase, is unlikely to reduce smoking prevalence to the endgame goal of $5 \%$ in the next five decades.

\section{INTRODUCTION}

In 1997, Taiwan established its first comprehensive policy package for tobacco control, the Tobacco Hazards Prevention Act (THPA), subsequently revised in 2009 to include pictorial health warnings, smoke-free worksites and restaurants and the banning of most tobacco advertising. In 2002, the Health and Welfare Surcharge on Tobacco Products (HWSTP) was introduced, and since then the tobacco levy has been periodically raised, the last hike being decreed in 2017. Retail cigarette prices have consequently increased, but smoking is still relatively cheap, with excise taxes currently constituting $<60 \%$ of the total price. The HWSTP has been used for cessation programmes and promotional campaigns, while the available budget for tobacco control has increased from over US $\$ 30$ million in $2003^{1}$ to over US\$50 million since 2009 onwards, ${ }^{2}$ making Taiwan's expenditures per capita ( US\$2.2) one of the highest in the world. ${ }^{34}$ As a result, the smoking rate fell from $30 \%$ in $2000^{5}$ to $20 \%$ in $2015 .^{6}$

Even though Taiwan has had some success in reducing tobacco use, smoking is still the largest cause of premature death. ${ }^{7}$ Per capita cigarette consumption has decreased only slightly in the last decade and remains one of the highest in Asia. ${ }^{8}$ Moreover, the rate of decline is slowing recently, making it unlikely for Taiwan to reach its overall goal to reduce smoking prevalence among adults to $10 \%$ by $2020 .^{9}$

Using simulation modelling, we first conducted a retrospective analysis aimed at evaluating the consequences of the measures adopted starting from 2000, including the crucial 2009 THPA amendment. We then considered two future scenarios, one in which the current tobacco control legislation remains unchanged, and another hypothesising full implementation of the MPOWER ${ }^{10}$ package. The computational tool employed in this study is SimSmoke, ${ }^{11} 12$ a well-established computational model that has been successfully tested and used in $>20$ countries, including, among others, Brazil, ${ }^{13}$ China, ${ }^{14}$ Italy, ${ }^{15}$ Korea ${ }^{16}$ and Thailand. ${ }^{17}$ An early version of SimSmoke had been applied in Taiwan in 2005 to predict the effect of the tax hike introduced in $2002,{ }^{18}$ when the country entered the World Trade Organisation.

\section{METHODS}

\section{SimSmoke overview}

SimSmoke is composed of three modules: population, smoking and policy, all working at discrete (yearly) simulation steps. Beginning from a baseline year (the starting point), the population module applies fertility and mortality rates to estimate the demographics trend over time, by age and gender. The smoking module uses age-specific and genderspecific rates for smoking, cessation and relapse, to subsequently divide the population into current, never and former smokers by years of cessation, and finally to provide, for each year, the smoking prevalence by age and gender. The processes simulated by these two modules are assumed Markovian of the first order, which means that the transition from 1 year to the next depends only on the present state of the variable. The policy module adjusts initiation and cessation rates, based on the level of implementation and enforcement of seven types of tobacco control policies, derived from the MPOWER package: taxation of tobacco products, clean air laws, mass media campaigns, advertising bans, health warnings, youth access enforcement and 
cessation treatment. Yearly attributable mortality is computed by age, gender and smoking status applying the corresponding relative risks. Further details are available elsewhere. ${ }^{11-18}$

\section{Input data}

The year chosen as the baseline for the simulation was 2000, while the length of the tracking period, that is the time interval defined by the user for inputting the historical policy data, which are needed to 'ground' the model's projections, was set to 17 years (2000-2016).

\section{Population module}

Taiwan's demographic data (mid-year population in 2000) and fertility rates (yearly values from 2000 to 2016) were retrieved from the Department of Household Registration website. ${ }^{19}$ Fertility rates, originally aggregated by 5 -year age groups, were assumed constant for single ages belonging to the same group. Mortality rates were acquired from the population database of the Department of Household Registration, ${ }^{20}$ and for each age and gender, the mean value calculated over the 2000-2016 period, was used.

\section{Smoking module}

Prevalence data for the baseline year were obtained from the Taiwan Social Change Survey (TSCS) conducted in $2000^{5}$ and focused on adults older than 21 years. Data relative to the $12-20$ age range were from a previous study, ${ }^{21}$ based on the Taiwan National Health Interview Survey (TNHIS). Adults' data were first aggregated in equally-width age groups and the corresponding frequencies of smokers were calculated. Age-specific values were then obtained by assigning the group value to the mid-point age, and subsequently linearly interpolating between the mid-point values.

Since neither TSCS nor TNHIS provide any information about the number of years since quitting, the percentage of former smokers by age, gender and time since cessation was estimated combining the rates included in the GBD Smoking Prevalence Database, ${ }^{22}$ with the aforementioned population and mortality data. Using those estimates, the yearly cessation rate was computed as the ratio between individuals who quit within the current year and smokers in the previous year.

Finally, due to lack of data for Taiwan, the US relapse rates ${ }^{23-25}$ were used as a starting base for a calibration procedure aimed at optimising the choice of gender-specific smoking rates. Specifically, we progressively modified relapse rates for first year since quitting and for between 1 and 2 years since quitting by gender, until the correspondence between simulated and real smoking rates was maximised. Further details on model performance assessment are available in the 'Simulations' section.

Smoker versus non-smoker relative risks for men and women older than 35 years of age were from a Taiwan-based study. ${ }^{26}$ The values in that study were much lower than those observed in the USA, at least partially due to different smoking behaviour. ${ }^{26}$ Due to lack of detailed local data for ex-smokers by years since quitting, we applied the default decreasing coefficients found in US studies in the $90 \mathrm{s.}^{25} 27$

\section{Policy module}

We inputted Policy Module data for each year from 2000 to 2016, based on the Tobacco Control Reports annually released by the Health Promotion Administration (HPA), ${ }^{28}$ and on information provided by scholars and antismoking non-governmental organisations. All parameters were further verified by five public health experts in Taiwan.

The annual average retail price per pack was retrieved from a market survey conducted by HPA using the WHO's average price definition, and then adjusted for inflation by entering the consumer price index, yearly estimated by the DirectorateGeneral of Budget, Accounting and Statistics. ${ }^{29}$ For the demand elasticity for cigarettes, we adopted the age-specific values applied in the earlier Taiwan SimSmoke. ${ }^{18}$

Taiwan was considered to have a moderate-to-strong smokefree legislation. Smoking has been banned in all workplaces and in most public spaces since 2009, except for working environments with fewer than three occupants, pubs, bars and nightclubs that open from 21:00 hours for adults. Due to some known discrepancies between urban and rural areas, the enforcement level was set to 6 out of 10 from 2000 to 2008 and to 8 out of 10 from 2009 to 2016.

Taiwan was categorised to be at the highest level in terms of tobacco control campaigns since 2009, due to the presence of a national agency (HPA), expenditures over US\$2 per capita, campaigns that often incorporate quit-lines and a national cessation programme. Before 2009, mass media campaigns were considered low funded from 2000 to 2005 and moderately funded from 2006 to 2008.

The amendment of the THPA in 2009 had extended the marketing ban to include every form of direct advertising on all kinds of media; however, indirect marketing strategies such as brand stretching (products other than cigarettes marked with cigarette brand name) or sponsorship of events are still allowed.

Health warnings were minimal in Taiwan until 2009, including only text messages without any pictorial images. Starting in 2009 , health warnings must cover $35 \%$ of both sides of the cigarette pack, which corresponds to the second-highest category of the MPOWER four-level scale ('a warning that covers at least $30 \%$ of the principal display area of the pack'). ${ }^{30}$

In terms of youth access enforcement, self-service and vending machines are banned over the entire country, and a well-enforced restriction on selling cigarettes to minors has been in place since 2009. Furthermore, community involvement has reached a good, although not optimal, level after the THPA amendment, being assigned a score of 50 out of 100 before 2009 and 70 out of 100 after 2009. Merchant awareness has evolved similarly, with an improvement in recent years that brought its level to 80 in 2014, and 90 in 2016.

Taiwan has provided a subsidised cessation since 2002 and the first quit-line in Asia since 2003. The programme continues to extend to more health facilities, including pharmacies, dental clinics and community health centres, and offered the highest subsidies in 2012. Nicotine replacement therapy is inexpensive (around 200 New Taiwan Dollar, NTD), but is only provided at no cost to very low-income individuals.

Brief interventions that involve advice and assistance in cessation by healthcare providers are implemented by a small proportion of designated clinics, compared with the level that the entire health professionals' body could achieve.

Policy levels are summarised in online supplementary appendix $\mathrm{A}$, all the data sources used in our simulations are listed in online supplementary appendix B and a list of key assumptions and limitations is provided in online supplementary appendix C.

\section{Simulations}

Model performance, that is, the agreement between observed and simulated data, was assessed by comparing the smoking 
Table 1 Policy levels and retail price of cigarettes for the four scenarios

\begin{tabular}{lllll}
\hline & Scenario & & & \\
\cline { 2 - 5 } & Status quo & Counterfactual & Full200 & Full300 \\
\hline Policy levels in 2000-2016 & $2000-2016$ & Year 2000 & $2000-2016$ & $2000-2016$ \\
Policy levels in 2017 & Year 2016 & Year 2000 & Year 2016 & Year 2016 \\
Retail price of cigarettes in 2017 & 100 NTD & 40.9 NTD & 100 NTD & 100 NTD \\
Policy levels from 2018 on & Year 2016 & Year 2000 & MPOWER fully implemented & MPOWER fully implemented \\
Retail price of cigarettes from 2018 on & 100 NTD & 40.9 NTD & 200 NTD & 300 NTD \\
\hline
\end{tabular}

rate provided by TSCS in $2000,{ }^{5} 2005,{ }^{31} 2010^{32}$ and $2015,{ }^{6}$ and the corresponding Taiwan SimSmoke output. In accordance with a recent study, ${ }^{33}$ the following indicators, uncorrelated and belonging to different evaluation metrics' categories, were computed: squared bias (SB), ${ }^{34}$ root mean squared relative error (RMSRE) ${ }^{35}$ coefficient of determination (CD) ${ }^{36}$ and modified modelling efficiency (EF1). ${ }^{37}$

The overall net impact of the interventions implemented from 2000 in Taiwan was estimated by first setting in each year all policies to their 2000 levels ('counterfactual' scenario) and then calculating the difference between the corresponding output and the output obtained with all policies currently in place ('status quo' scenario).

Future smoking rates and smoking-attributable deaths (SADs) were also simulated under two scenarios, assuming full implementation of the MPOWER package starting from 2018 with a retail cigarette price increase from 100 NTD to 200 NTD per pack ('Full200' scenario), and from 100 NTD to 300 NTD per pack ('Full300' scenario), respectively. Full200 and Full300 included total smoke-free air laws, a complete ban on direct and indirect advertising, well-funded mass media campaigns, strong pictorial warnings, comprehensive smoking cessation services and strict youth access policies. Note that for all future projections, the parameterisation for year 2017 was set equal to the status quo scenario, incorporating the last tax hike of 20 NTD in effect from June 2017. The main features of the four future scenarios are summarised in table 1 .

\section{RESULTS}

\section{Model performance evaluation}

Taiwan SimSmoke simulates satisfactorily the smoking prevalence among men and in total over the period 2000-2015 (figure 1), as also shown by the performance assessment in table 2. The difference between observed and predicted values is quite small, in terms of both average error $(\mathrm{SB}=9.61 \mathrm{E}-06$ among men and 6.28E-05 overall) and relative error (RMSRE $=4.12 \%$ among men and $4.11 \%$ overall). Moreover, the model is able to explain most of the total variance in the observed data (CD close to 1), and describes the behaviour of the observed data better than the average of the observations (EF1 positive and close to 1). The women's trend is considerably underestimated (figure 1). However, due to the small number of smokers among women in Taiwan, this result has little impact on the overall predictive power of the model and on its reliability.

\section{Impact of policies implemented since 2000}

Under current tobacco control policies (status quo scenario), mainly stipulated by the 2009 laws and incorporating the 2017 tax increase, the smoking rate among all adults is projected to decline in absolute terms by $3.3 \%$ (14.8\% in relative terms) from $22.2 \%$ in 2010 to $18.9 \%$ in 2020 , by $4.8 \%$ (21.5\% in relative terms) in 2030 , by $7.6 \%$ (34.3\% in relative terms) in 2050 and by $8.3 \%$ (37.4\% in relative terms) in 2060 . By gender, the reductions projected during the same years are: $0.4 \%$ (9.8\%), $0.6 \%$ (13.3\%), $0.9 \%(21.3 \%)$ and $1.1 \%(25.3 \%)$ for women; $6.9 \%$ (18.4\%), 10.2\% (27.2\%), 15.3\% (40.7\%) and 16.6\% (44.0\%) for men (table 3 ). The smoking rate is projected to reach approximately $15 \%$ by 2046 and $14 \%$ by 2057 , exhibiting a slow but constant decrease. Starting from the percentage of never smokers among men in 2010 (41.3\%), the relative decrease is expected to range between $-4.2 \%$ in 2020 and $-50.8 \%$ in 2060, as a consequence of a stable percentage of projected former smokers over time $(21.0 \%$ in $2010,23.8 \%$ in $2020,24.0 \%$ in $2030,22.6 \%$ in $2040,19.9 \%$ in 2050 and $16.6 \%$ in 2060). However, the same

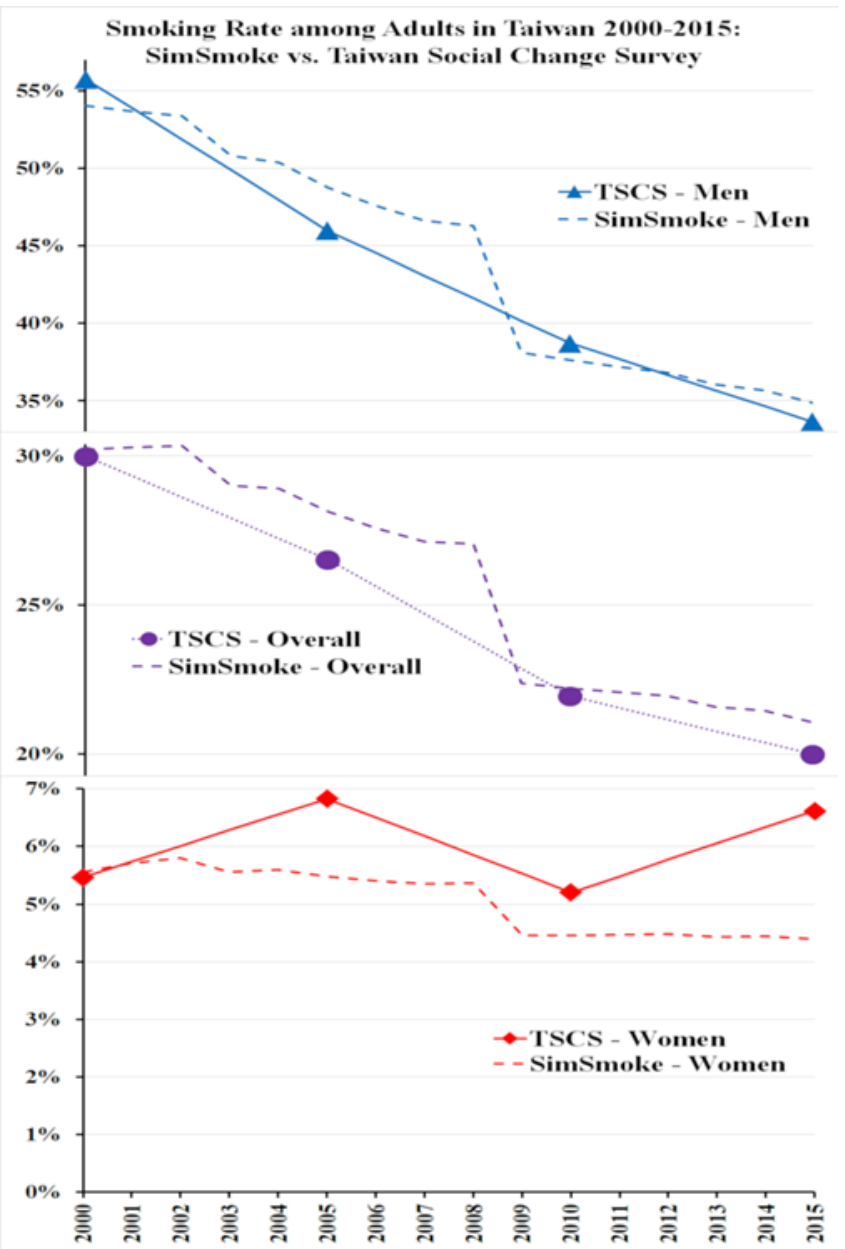

Figure 1 Smoking prevalence among adults (aged 18+ years) in Taiwan over the 2000-2015 period: comparison between simulated (Taiwan SimSmoke) and measured (Taiwan Social Change Survey (TSCS)) data by gender. 
Table 2 Performance evaluation of Taiwan SimSmoke in terms of smoking rate by gender group, over the 2000-2015 period

\begin{tabular}{llclc}
\hline Gender group & SB & RMSRE (\%) & CD & EF1 \\
\hline Men & $9.61 \mathrm{E}-06$ & 4.12 & 0.90 & 0.77 \\
Women & $1.11 \mathrm{E}-04$ & 20.80 & 2.83 & -0.58 \\
Overall & $6.28 \mathrm{E}-05$ & 4.11 & 1.02 & 0.78 \\
\hline
\end{tabular}

Perfect fit: $\mathrm{SB}=0, \mathrm{RMSRE}=0 \%, \mathrm{CD}=1, \mathrm{EF} 1=1$.

$C D$, coefficient of determination; EF1, modified modelling efficiency; RMSRE, root mean squared relative error; SB, squared bias.

relative decrease among women is between -0.5 and $-2.4 \%$, due to former smoker rates below $1 \%$.

The counterfactual scenario produces a much slower decline in smoking prevalence (table 3). Estimated as a decreasing trend independent of any policy intervention, it is used for calculating the net contribution of the 2009 amendment and of the other measures adopted starting from 2000. Thus, computing the difference between counterfactual and status quo and then dividing it by the 2000 smoking rate, we can estimate that the relative decrease in smoking prevalence attributable to tobacco control policies actually implemented in Taiwan was $26.7 \%$ in 2010 and $29.6 \%$ in 2015 , while would be $40.4 \%$ in $2030,45.6 \%$ in 2050 and $48.0 \%$ in 2060 .

Under the status quo scenario, the predicted annual number of SADs in 2017 was 19594 for men and 2245 for women. Attributable mortality among men is projected to keep increasing until 2038 (22 992 yearly deaths), and to drop again below 19000 by 2055. With respect to the yearly SADs estimated in 2010 (18 440), the relative increase is expected to be $5.6 \%$ by $2020,17.1 \%$ by 2030 and $24.3 \%$ by 2040 . On the other hand, with policy levels unchanged since 2000, annual yearly SADs are $>30000$ from 2033 to 2057, are a maximum in 2042 (32 906) and never fall

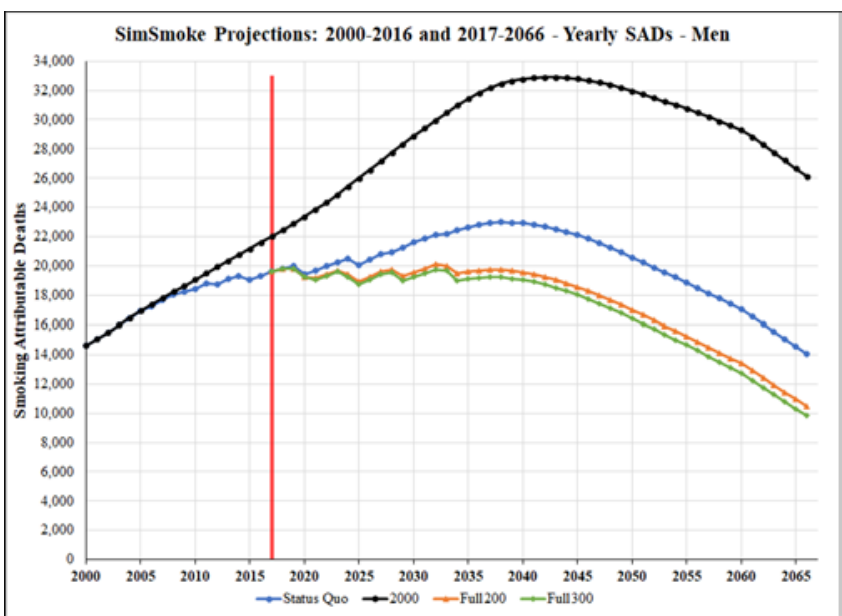

Figure 2 Taiwan SimSmoke projections 2000-2016 and 2017-2066: yearly smoking-attributable deaths (SADs) among men.

below 22000 (figure 2). Focusing on women, the annual smoking attributable mortality exhibits its peak much later (3878 deaths in 2056), with virtually no decrease until 2057. Moreover, from 2010 to 2041 SADs are projected to double, from 1834 to 3681. As before, the counterfactual scenario follows a similar trend as the status quo, but with much higher values (figure 3).

Tobacco control interventions implemented since 2000 are estimated to have averted $>9000$ lives by 2015 , as SimSmoke predicts 306867 SADs cumulated from 2000 to 2015 under the status quo scenario and 316085 under the counterfactual scenario. With respect to the future projections, the differences between the two scenarios are 24967 by 2020,89145 by 2030,188359 by 2040 , 311451 by 2050 and 451824 by 2060 (table 4 ).

Table 3 Smoking rate by gender, as simulated by Taiwan SimSmoke

\begin{tabular}{|c|c|c|c|c|c|c|c|c|c|}
\hline Gender & Scenario & & 2010 & 2015 & 2020 & 2030 & 2040 & 2050 & 2060 \\
\hline \multirow[t]{8}{*}{ Overall } & Status Quo & Current smokers & $22.2 \%$ & $21.1 \%$ & $18.9 \%$ & $17.4 \%$ & $15.8 \%$ & $14.6 \%$ & $13.9 \%$ \\
\hline & & Never smokers & $67.1 \%$ & $68.3 \%$ & $69.7 \%$ & $71.6 \%$ & $74.1 \%$ & $76.9 \%$ & $79.6 \%$ \\
\hline & Counterfactual & Current smokers & $30.3 \%$ & $30.0 \%$ & $30.1 \%$ & $29.7 \%$ & $28.8 \%$ & $28.4 \%$ & $28.4 \%$ \\
\hline & & Never smokers & $65.3 \%$ & $65.5 \%$ & $65.3 \%$ & $65.3 \%$ & $65.9 \%$ & $66.3 \%$ & $66.5 \%$ \\
\hline & Full200 & Current smokers & /I & /I & $15.2 \%$ & $13.4 \%$ & $11.6 \%$ & $10.3 \%$ & $9.5 \%$ \\
\hline & & Never smokers & /l & /I & $70.3 \%$ & $72.8 \%$ & $75.9 \%$ & $79.3 \%$ & $82.9 \%$ \\
\hline & Full300 & Current smokers & /I & /I & $14.4 \%$ & $12.6 \%$ & $10.8 \%$ & $9.5 \%$ & $8.7 \%$ \\
\hline & & Never smokers & /l & /l & $70.5 \%$ & $73.2 \%$ & $76.4 \%$ & $79.9 \%$ & $83.7 \%$ \\
\hline \multirow[t]{8}{*}{ Women } & Status Quo & Current smokers & $4.5 \%$ & $4.4 \%$ & $4.0 \%$ & $3.9 \%$ & $3.7 \%$ & $3.5 \%$ & $3.3 \%$ \\
\hline & & Never smokers & $93.4 \%$ & $93.6 \%$ & $93.9 \%$ & $94.3 \%$ & $94.8 \%$ & $95.1 \%$ & $95.6 \%$ \\
\hline & Counterfactual & Current smokers & $6.2 \%$ & $6.3 \%$ & $6.5 \%$ & $6.6 \%$ & $6.7 \%$ & $6.9 \%$ & $6.9 \%$ \\
\hline & & Never smokers & $92.9 \%$ & $92.8 \%$ & $92.8 \%$ & $92.7 \%$ & $92.7 \%$ & $92.6 \%$ & $92.5 \%$ \\
\hline & Full200 & Current smokers & /l & $/ /$ & $3.2 \%$ & $3.0 \%$ & $2.7 \%$ & $2.5 \%$ & $2.3 \%$ \\
\hline & & Never smokers & /l & /l & $94.1 \%$ & $94.6 \%$ & $95.2 \%$ & $95.7 \%$ & $96.3 \%$ \\
\hline & Full300 & Current smokers & /l & /l & $3.0 \%$ & $2.8 \%$ & $2.5 \%$ & $2.3 \%$ & $2.1 \%$ \\
\hline & & Never smokers & /l & /l & $94.1 \%$ & $94.7 \%$ & $95.3 \%$ & $95.9 \%$ & $96.5 \%$ \\
\hline \multirow[t]{8}{*}{ Men } & Status Quo & Current smokers & $37.6 \%$ & $34.9 \%$ & $30.7 \%$ & $27.4 \%$ & $24.3 \%$ & $22.3 \%$ & $21.1 \%$ \\
\hline & & Never smokers & $41.3 \%$ & $43.2 \%$ & $45.5 \%$ & $48.6 \%$ & $53.1 \%$ & $57.8 \%$ & $62.3 \%$ \\
\hline & Counterfactual & Current smokers & $51.6 \%$ & $50.5 \%$ & $50.0 \%$ & $48.5 \%$ & $46.5 \%$ & $45.5 \%$ & $45.0 \%$ \\
\hline & & Never smokers & $38.2 \%$ & $38.4 \%$ & $37.9 \%$ & $37.5 \%$ & $38.3 \%$ & $38.8 \%$ & $39.0 \%$ \\
\hline & Full200 & Current smokers & /I & /I & $24.5 \%$ & $20.6 \%$ & $17.3 \%$ & $15.3 \%$ & $13.9 \%$ \\
\hline & & Never smokers & /I & /I & $46.6 \%$ & $50.9 \%$ & $56.4 \%$ & $62.3 \%$ & $68.2 \%$ \\
\hline & Full300 & Current smokers & /I & /I & $23.2 \%$ & $19.3 \%$ & $16.1 \%$ & $14.0 \%$ & $12.7 \%$ \\
\hline & & Never smokers & // & /l & $46.9 \%$ & $51.5 \%$ & $57.2 \%$ & $63.4 \%$ & $69.6 \%$ \\
\hline
\end{tabular}




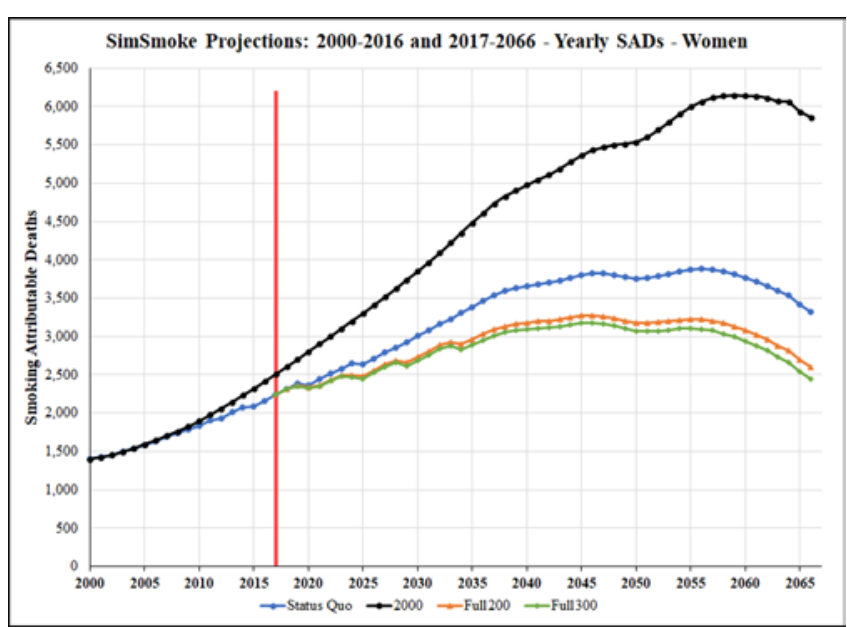

Figure 3 Taiwan SimSmoke projections 2000-2016 and 2017-2066: yearly smoking-attributable deaths (SADs) among women.

\section{Potential impact of future policies}

Turning to potential increase of future policies, the simulation under the Full200 scenario projects that the smoking prevalence should drop below $10 \%$ by 2054 , with $14.7 \%$ among men and $2.4 \%$ among women. The second alternative (Full300 scenario) is more effective, projecting the total smoking rate to be $<10 \%$ by 2047 and the men smoking rate $<15 \%$ by 2045 .

Under both optimal scenarios, the number of yearly SADs among men never exceeds 20 100, displays a fluctuating trend between 2015 and 2035 and then constantly declines starting in 2038. Among women, yearly SADs always fall below 3500 and start decreasing in 2055. Focusing on the cumulative values, table 4 shows that fully implementing the MPOWER package and doubling the retail price of cigarettes (Full200), would allow to save $>13000$ lives by $2030,>45000$ by $2040,>85000$ by 2050 and almost 130000 by 2060 . Further increasing cigarette prices to 300 NTD (Full300), Taiwan would avert $>15000$ deaths by $2030,>53000$ by $2040,>100000$ by 2050 and $>150000$ by 2060 .

\section{DISCUSSION}

The goal of the present research was to simulate and analyse past smoking rates and SADs in Taiwan and to predict future trends, exploiting the short-term and long-term projections provided by SimSmoke, a dynamic simulation model developed for estimating the potential impact of tobacco control policies on smoking prevalence and attributable mortality. Based on our simulations, Taiwan's smoking rate decreased by almost $29 \%$ among men in 16 years, due to the measures implemented from 2000 to 2015. Moreover, hypothesising the MPOWER package fully implemented and the price of cigarettes doubled in 2018, we project a potential reduction of $39.6 \%$ in 20 years (from $22.2 \%$ in 2010 to $13.4 \%$ in 2030 ), and of $47.6 \%$ in 30 years (from $22.2 \%$ in 2010 to $11.6 \%$ in 2040), as displayed in table 3.

While the immediate impact of tobacco control policies on smoking rate is substantial, the effect on the number of SADs in the short term is expected to be limited, because of the burden of past smoking prevalence. Taiwan SimSmoke estimates that, if current policies continue, the cumulative (from 2000) number of SADs will reach 1000000 in 2044, that is, in only 26 years from now. On the other hand, even an immediate implementation of the MPOWER package at the highest level would cumulatively save only about 60000 (Full200) and 70000 (Full300) lives by the same year.

The WHO MPOWER policies are effective and comprehensive tobacco control measures focused on reducing demand, which, if adopted at the highest level, would achieve the global tobacco control target of $30 \%$ relative reduction by 2020 , ahead of the timeline. However, even with a full implementation, the Taiwan simulations project that the smoking rate trend eventually flattens and does not reach the endgame target of 5\% in the next 50 years. However, results from the counterfactual scenario in table 4 show a large increase in lives saved by the current policies in comparison with remaining at 2000 policies, and the deaths further averted under the two optimal scenarios. The relative difference between SADs projected under the status quo scenario and SADs projected under the counterfactual scenario is $20.7 \%$ in $2040,26.7 \%$ in 2050 and $32.5 \%$ in 2060 . On the other hand, the relative differences between status quo and Full200 are projected as 5.1\% in 2040, 7.4\% in 2050 and $9.3 \%$ in 2060, while under Full300 the relative differences are 5.9\%, $8.6 \%$ and $10.8 \%$.

Taiwan SimSmoke outcomes are generally consistent with previous studies based on the same modelling tool. In particular, comparing the Taiwan results with other countries that implemented strong policies, yields comparable results. The relative decline in male smoking rates to the policies introduced between 2000 and $2015(28.8 \%)$ is similar to the reduction estimated in Thailand (25\% from 1991 to 2006$),{ }^{17}$ South Korea (17\% from 1995 to 2006) ${ }^{16}$ and Brazil (50\% from the longer period of 1989-2008 and with larger price increases). ${ }^{13}$ In addition, other SimSmoke projections also indicate that implementing complete MPOWER measures still yields smoking rates substantially above $5 \% .^{14} 15$

Tobacco control experience in Taiwan, as quantified by SimSmoke simulations, indicates that there is a need to rethink the current approach. While there have been major gains, at the same time, more can be done. Policymakers should integrate traditional measures with innovative methods including tobacco endgame proposals in response to the constant evolution of

\begin{tabular}{|c|c|c|c|c|c|c|c|c|}
\hline Gender & Scenario & 2010 & 2015 & 2020 & 2030 & 2040 & 2050 & 2060 \\
\hline \multirow[t]{4}{*}{ Women } & Status quo & 17584 & 27599 & 39077 & 66186 & 100225 & 137868 & 176126 \\
\hline & Counterfactual & 17743 & 28474 & 41498 & 75136 & 120281 & 173697 & 233287 \\
\hline & Full200 & /I & II & 39017 & 64559 & 94638 & 126941 & 158752 \\
\hline & Full300 & /I & /l & 39007 & 64276 & 93652 & 124992 & 155561 \\
\hline \multirow[t]{4}{*}{ Men } & Status quo & 184204 & 279268 & 377474 & 583049 & 809075 & 1027828 & 1214564 \\
\hline & Counterfactual & 185801 & 287611 & 400021 & 663244 & 977378 & 1303450 & 1609227 \\
\hline & Full200 & /l & /l & 377074 & 571265 & 768700 & 952264 & 1102727 \\
\hline & Full300 & /l & /1 & 377007 & 569366 & 762322 & 940423 & 1084769 \\
\hline
\end{tabular}


new products and strategies by the tobacco industry. Moreover, greater attention should be directed towards socially and economically disadvantaged populations. In particular, ad hoc studies aimed at investigating the response of lower socioeconomic groups need to be conducted, as it has been demonstrated that the main interventions recommended by the Framework Convention on Tobacco Control ${ }^{38}$ generally do not reduce social inequalities in smoking, ${ }^{39}$ except for higher taxation. ${ }^{40}$ It is of paramount importance to prevent the reductions in smoking to have limited impact on the poorer social classes. Furthermore, in addition to MPOWER demand-side policies, supply side interventions against illicit trade, tobacco industry interference and duty-free sales, together with novel measures such as regulating content in tobacco products, and promoting campaigns for tobacco industry denormalisation, will need to be introduced or strengthened.

Like other simulation-based studies, the results depend on limitations intrinsic to the model, which by definition provides a simplified representation of reality, and on the quality and availability of input data. SimSmoke does not take into account the recent proliferation of electronic cigarettes, which may play a role as gateway to conventional smoking among youth, ${ }^{41}$ and act as a facilitator of smoking cessation among adults. ${ }^{42}$ Betel quid chewing, which is a widespread practice in Taiwan, is not part of the model as well, and may have affected the accuracy of our simulations due to its strong relationship with smoking behaviour (the great majority of chewers are smokers) and due to its health effects in combination with smoking. ${ }^{43}$ In addition, the age-specific mortality rates are constant over all future years, which may overestimate SADs especially in later years. However, SAD may be underestimated, because smoker relative mortality risks were based on recent cigarette use in Taiwan and may be expected to increase over time to the levels in highincome nations. In addition, we do not consider deaths due to second-hand smoke, which is likely to be important for women. With regard to input availability, we lacked nationally representative data in Taiwan for relapse rates, cessation rates and the percentage of former smokers by years since quitting. However, several previous SimSmoke models adopted US relapse rates, and predicted well. ${ }^{13-17}$ Moreover, the percentage of former smokers resulting from our estimations was consistent with the data reported in the TNHIS ${ }^{2144}$ (which do not distinguish by years since quitting). Finally, we were unable to capture well trends

\section{What this paper adds}

- The demand-side MPOWER measures, as recommended by WHO, have long proven to be effective in reducing tobacco use.

- It is not clear whether the current declining trend, partly due to MPOWER implementation, will continue until achieving a tobacco endgame or will encounter a plateau in the next future.

- Our study shows that in a relatively high-performing country like Taiwan, which had significant success in reducing tobacco use in the past, the current WHO MPOWER policies, even if fully implemented with a large tax increase, will not achieve the $5 \%$ endgame smoke-free society target in the next five decades.

- The impact of the MPOWER measures is expected to weaken over time. Thus, new policies should be considered to prevent tobacco use from levelling off in the next few decades. in female smoking rates, although substantially lower than male rates. Better information is needed on female initiation rates.

\section{CONCLUSION}

Taiwan SimSmoke shows that full implementation of the MPOWER package with a large increase in the retail price of cigarettes could significantly reduce the smoking rate, even in a country where those measures have already been adopted at a moderate-to-strong level. However, the simulations also show that the effects on SADs are limited, and that the $5 \%$ endgame target will not be achieved in the next few decades without more drastic measures.

Correction notice Please note this article has been updated since published Online First. A column in Table 3 was previously omitted.

Acknowledgements The authors wish to thank the Health Promotion Administration and the John Tung Foundation for their help in the data collection process.

Contributors DTL designed the original model and the computational framework. MS and WG collected, organised and analysed the data. MS carried out the implementation, performed the calculations and ran the simulations. MS and WG wrote the manuscript with input from all the coauthors. Y-WC, H-YC, Y-HC and C-PW provided critical feedback on policy implementation and helped to shape the research. WG conceived the study and was in charge of overall direction and planning. All coauthors discussed the results, commented on the manuscript and approved the final version. MS and WG are co-first authors.

Funding This work was funded by the Health Promotion Administration, Ministry of Health and Welfare, Taiwan (ROC), with funding from the Health and Welfare Surcharge on Tobacco Products (grant number: 03724606, project code: 1051218107).

Disclaimer The Health Promotion Administration had no role in the study design, collection, analysis or interpretation of the data, writing the manuscript or the decision to submit the paper for publication.

Competing interests None declared.

Patient consent for publication Not required.

Provenance and peer review Not commissioned; externally peer reviewed.

Open access This is an open access article distributed in accordance with the Creative Commons Attribution Non Commercial (CC BY-NC 4.0) license, which permits others to distribute, remix, adapt, build upon this work non-commercially, and license their derivative works on different terms, provided the original work is properly cited, appropriate credit is given, any changes made indicated, and the use is non-commercial. See: http://creativecommons.org/licenses/by-nc/4.0/.

\section{ORCID iD}

Mattia Sanna http://orcid.org/0000-0001-7262-0856

\section{REFERENCES}

1 BHP. Taiwan tobacco control annual report. Taipei City, Taiwan: Bureau of Health Promotion, Department of Health, Taiwan, 20052005.

2 National Development Council, Taiwan. Fiscal year 2017 budget for subsidiary units for tobacco control and health promotion funds. Taipei, Taiwan: Government Open Data Platform, 2017.

3 Stoklosa M, Ross H. Tobacco control funding for low-income and middle-income countries in a time of economic hardship. Tob Control 2014;23(e2):e122-6.

4 Joossens L, Raw M. The Tobacco Control Scale 2016 in Europe. Brussels, Belgium: Association of European Cancer Leagues (ECL), 2016.

5 Chang YH, YC F. 2000 Taiwan social change survey (round 4, year 1): interpersonal relations, leisure, family, life experiences, mental health (C00108_2)[Data file]. Taipei City, Taiwan: Survey Research Data Archive, Center for Survey Research, Research Center for Humanities and Social Sciences, Academia Sinica, 2001.

6 YC F. 2015 Taiwan social change survey (round 7, year 1): globalization, work, family, mental health, religion, mass communication, political participation, Leisure (C00315_1) [Data file]. Taipei City, Taiwan: Survey Research Data Archive, Center for Survey Research, Research Center for Humanities and Social Sciences, Academia Sinica, 2016

7 GBD, 2016. Global Burden of Disease Study 2016 Results Seattle (United States of America): Institute for Health Metrics and Evaluation (IHME) https://http://vizhub. healthdata.org/gbd-compare/ (accessed Sep 2017).

$8 \mathrm{Ng} \mathrm{M}$, Freeman MK, Fleming TD, et al. Smoking prevalence and cigarette consumption in 187 countries, 1980-2012. JAMA 2014;311:183-92. 
9 HPA. Taiwan tobacco control annual report. Taipei City, Taiwan: Health Promotion Administration, Ministry of Health and Welfare, Taiwan, 20132013.

10 WHO. MPOWER: a policy package to reverse the tobacco epidemic. Geneva, Switzerland: World Health Organization, 2008.

11 Levy DT, Cummings KM, Hyland A. A simulation of the effects of youth initiation policies on overall cigarette use. Am J Public Health 2000;90:1311-4.

12 Levy DT, Friend K, Holder $\mathrm{H}$, et al. Effect of policies directed at youth access to smoking: results from the SimSmoke computer simulation model. Tob Control 2001;10:108-16.

13 Levy D, de Almeida LM, Szklo A. The Brazil SimSmoke policy simulation model: the effect of strong tobacco control policies on smoking prevalence and smokingattributable deaths in a middle income nation. PLoS Med 2012;9:e1001336.

14 Levy D, Rodríguez-Buño RL, Hu TW, et al. The potential effects of tobacco control in China: projections from the China SimSmoke simulation model. BMJ 2014;348:g1134.

15 Levy D, Gallus S, Blackman K, et al. Italy SimSmoke: the effect of tobacco control policies on smoking prevalence and smoking attributable deaths in Italy. BMC Public Health 2012;12:709.

16 Levy DT, Cho SI, Kim YM, et al. SimSmoke model evaluation of the effect of tobacco control policies in Korea: the unknown success story. Am J Public Health 2010; 100:1267-73.

17 Levy DT, Benjakul S, Ross H, et al. The role of tobacco control policies in reducing smoking and deaths in a middle income nation: results from the Thailand SimSmoke simulation model. Tob Control 2008;17:53-9.

18 Levy DT, Wen CP, Chen TY, et al. Increasing taxes to reduce smoking prevalence and smoking attributable mortality in Taiwan: results from a tobacco policy simulation model. Tob Control 2005; 14(Suppl 1):i45-50.

19 Department of Household Registration, Ministry of the Interior, Taiwan, 2017. Statistics http://www.ris.gov.tw/en/web/ris3-english/history (accessed Sep 2017).

20 Department of Household Registration, Ministry of the Interior, Taiwan, 2017. Demographics http://www.ris.gov.tw/346 (accessed Sep 2017).

21 Wen CP, Levy DT, Cheng TY, et al. Smoking behaviour in Taiwan, 2001. Tob Control 2005; 14(Suppl 1):i51-i55.

22 GBD. Global Burden of Disease Study 2015 Smoking Prevalence 1980-2015. Seattle, USA: Institute for Health Metrics and Evaluation (IHME), 2015.

23 Gilpin EA, Pierce JP, Farkas AJ. Duration of smoking abstinence and success in quitting. J Natl Cancer Inst 1997;89:572-6.

24 Hughes JR, Keely J, Naud S. Shape of the relapse curve and long-term abstinence among untreated smokers. Addiction 2004;99:29-38.

25 U.S. Department of Health and Human Services. The Health Benefits of Smoking Cessation - a report of the Surgeon General. DHHS Publication No (CDC) 90-8416. Rockville, USA: U.S. Department of Health and Human Services, Public Health Service, Centers for Disease Control, Center for Chronic Disease Prevention and Health Promotion, Office of Smoking and Health, 1990.

26 Wen CP, Tsai SP, Chen CJ, et al. The mortality risks of smokers in Taiwan: Part I: causespecific mortality. Prev Med 2004;39:528-35.

27 Institutes NH. National Cancer Institute. Changes in Cigarette-Related Disease Risks and Their Implication for Prevention and Control. In: Burns DM, Garfinkel L, Samet JM, eds. Smoking and Tobacco Control Monograph 8. Bethesda,USA: Smoking and Tobacco Control Program, National Cancer Institute, Donald R. Shopland, 1997:565.
28 HPA. Health Education and Tobacco Control: Health Promotion Administration, Ministry of Health and Welfare, Taiwan. 2017 https://www.hpa.gov.tw/EngPages/ EngTopicList.aspx?nodeid=1069 (accessed Dec 2017).

29 Directorate-General of Budget, Accounting and Statistics, Executive Yuan, Taiwan. Consumer Price Index. 2017 https://eng.stat.gov.tw/ct.asp?xltem=12092\&ctNode= 1558\&mp $=5$ (accessed Dec 2017).

30 WHO. Report on the global tobacco epidemic, 2008: the MPOWER package. Geneva, Switzerland: World Health Organization, 2008

31 Chang Y-H, Y-c F. Taiwan Social Change Survey: (Round 5, Year 1): Globalization, Work Family, Mental Health (CO0153_1) [Data file]. Taipei City, Taiwan: Survey Research Data Archive, Center for Survey Research, Research Center for Humanities and Social Sciences, Academia Sinica, 2006.

32 Chang Y-H, S-h T, Liao P-S. Taiwan Social Change Survey (Round 6, Year 1): Globalization, Work, Family, Mental Health, Religion, Mass Communication, Political Participation, Leisure (C00221_1) [Data file]. Taipei City, Taiwan: Survey Research Data Archive, Center for Survey Research, Research Center for Humanities and Social Sciences, Academia Sinica, 20102012.

33 Sanna M, Bellocchi G, Fumagalli M, et al. A new method for analysing the interrelationship between performance indicators with an application to agrometeorological models. Environmental Modelling \& Software 2015;73:286-304

34 Kobayashi K, Salam MU. Comparing simulated and measured values using mean squared deviation and its components. Agron J 2000;92:345-52.

35 Busemeyer L, Ruckelshausen A, Möller K, et al. Precision phenotyping of biomass accumulation in triticale reveals temporal genetic patterns of regulation. Sci Rep 2013:3:2442.

36 Loague K, Green RE. Statistical and graphical methods for evaluating solute transport models: Overview and application. J Contam Hydrol 1991;7:51-73.

37 Yang J, Greenwood DJ, Rowell DL, et al. Statistical methods for evaluating a crop nitrogen simulation model, N_ABLE. Agric Syst 2000;64:37-53.

38 WHO. WHO Framework Convention on Tobacco Control. Geneva (Switzerland: World Health Organization, 2003.

39 Hill S, Amos A, Clifford D, et al. Impact of tobacco control interventions on socioeconomic inequalities in smoking: review of the evidence. Tob Control 2014;23:e89-97.

40 Global Tobacco Economics Consortium. The health, poverty, and financial consequences of a cigarette price increase among 500 million male smokers in 13 middle income countries: compartmental model study. BMJ 2018;361:k1162.

41 Chatterjee $K$, Alzghoul B, Innabi A, et al. Is vaping a gateway to smoking: a review of the longitudinal studies. Int J Adolesc Med Health 2016;30:20160033.

42 McNeill AD, Brose LS, Calder RI, et al. Evidence review of e-cigarettes and heated tobacco products 2018. A report commissioned by Public Health England. London, UK: Public Health England, 2018:243

43 Wen CP, Tsai SP, Cheng TY, et al. Uncovering the relation between betel quid chewing and cigarette smoking in Taiwan. Tob Control 2005;14(Suppl 1):i16-22.

44 Cheng T-Y, Wen C-P, Tsai M-C. The current status of smoking behavior in Taiwan: data analysis from National Health Interview Survey in 2001. Taiwan Journal of Public Health 2003;22:453-64. 